\title{
An Empirical Study on Factors Influencing the Intention to use Mobile Learning
}

\author{
Malik Khlaif Gharaibeh ${ }^{1, *}$, Natheer Khlaif Gharaibeh ${ }^{2}$ \\ ${ }^{1}$ School of Business, Jadara University, Irbid, 21110, Jordan \\ ${ }^{2}$ College of Computer Science and Engineering, Taibah University, Yanbu, 41911, Saudi Arabia
}

\author{
A R T I C L E IN F O \\ Article history: \\ Received: 26 July, 2020 \\ Accepted: 18 October, 2020 \\ Online: 24 October, 2020
}

Keywords:

Mobile learning

ISSM

Trust

\begin{abstract}
A B S T R A C T
Lately, the use of mobile learning has increased in higher education at a global level. Especially after the new Coronavirus (Covid-19). Therefore, trust issues towards the benefits of mobile learning are still important matters just as important as quality dimensions (e.g. service quality, information quality and system quality) for both technology and its content. These three factors are existing in the Information System Success Model (ISSM), but the trust is not clearly present. Hence, this study is attempting to explain the impact of trust in addition to the three quality dimensions of the ISSM on the usage intention of mobile learning among students in two Jordanian universities. The data were gathered by a self-administered questionnaire and SPSS version 23 is used by performing linear regression analysis to analyze it. The findings showed that trust, service quality, system quality, and information quality positively and significantly affect the intention to use mobile learning. This study will help researchers, decision-makers and system designers by gaining valuable implications in developing proper strategies and creating effective and practical approaches through learning via mobile devices.
\end{abstract}

\section{Introduction}

Because of rapid development and increasing capabilities of technology and the progress of 4th industrial revolution in the last two decades, many business transformations have emerged, mobile applications are considered one of the most important transformations, as a result, many applications have been developed in the field of education. For that reason, the academic sector is making great efforts to activate and introduce this new method of smart learning in its environment [1-3]. Such service encourages researches to study this type of technology in terms of its effect on students [4], whether it is university or school Mobile learning occupied important role in the educational process [5]. The goal of this research is to make effective use of mobile applications in the educational sector especially after the global emergence of Coronavirus, which caused difficulties and frustrations for both teachers and students.

Mobile learning can be defined as "learning across multiple contexts, through social and content interactions, using personal electronic devices" [6]. The article [7] claimed that mobile learning is an extension of electronic learning in which a

${ }^{*}$ Corresponding Author: Malik Khlaif Gharaibeh, Address: Jadara University, Contact No: 00962779919484 \& Email: malik.gh@jadara.edu.jo smartphone is used. In more detail, Mobile learning technology changed the way students and learners manage learning activities with one another, and also facilitated knowledge sharing between them [8-10]. Also, The paper [11] indicated that mobile learning is not only limited to a mobile device but also includes learning via any portable phone e.g. PDA and tablet. In short, it is a technology that allows students to carry out their daily educational work with higher quality, in addition to its advantage that it is portable and it can be used regardless of location and time $[5,12]$.

There are many features and functions that mobile learning offers to students, such as downloading books and study materials, making phone calls, responding to e-mail quickly, capturing pictures, and interacting easily with lecturers and colleagues outside the campus $[13,14]$. Mobile learning also provides benefits to universities in that it provides multiple educational services for students at a relatively low cost $[15,16]$. Mobile learning is a very important step for any educational institution because that gives it a competitive advantage and in the near future the use of these services in educational institutions will be inevitable, especially in universities [17].

At present, it seems that the application of the mobile learning service faces technical and un-technical restrictions (such as any 
new technology in developing countries), thus the rate of adoption of this service is less than expected [18-20]. The paper [21] pointed out that students need a deeper and broader understanding of how to use these applications. Form a theoretical perspective, a few studies have been measured on the adoption of university students for mobile learning in Jordan. Hence, it is a good idea to study this spreading technology. Given that Jordan has a good wireless network infrastructure and penetration rate of mobile phones is high [22]. Statistics revealed that 90 percent of Jordanian families have a smartphone, around also 89 percent have an Internet subscription [23-25]. More specifically, Jordan has enhanced its $4 \mathrm{G}$ coverage and its improvement is directed towards mobile terminals. It also has got high in both mobile broadband and smartphone penetration rate [26-29].

This study attempts to explain the determinants affecting the adoption intention to use mobile learning among university students'. The current study adds to the prior work on mobile learning in two points. First, previous researches shed light on TAM, IDT, and UTAUT in studying mobile learning acceptance/adoption/intention to use e.g. [30-32]. Despite the important role of trust in technology, the relationship between students' trust and adoption intention in the context of mobile learning has rarely been examined [32]. This study interested in investigating the relationship between trust and intention to use mobile learning. Second, whereas previous research was more concerned with the influence of the innovation characteristics and new technology, which already exists in TAM, UTAUT, and IDT. This study takes another direction by incorporating quality dimensions with trust to explore the factors of intention to use mobile learning among students'.

\section{Theoretical Foundation and Hypothesis Development}

ISSM is extensively adapted among researchers to investigate the acceptance/adoption of many information systems [33-35] (see Figure 1). The article [36] Stated that ISSM is a robust model because it has a solid theoretical basis for many successful empirical types of research. This model consists of three independent variables that affect positively the intention of use and acceptance. "System quality is defined as the degree to which the system users believe that a system is easy to use, user-friendly, easy to learn, easy to connect to, and enjoyable to use" [37]. "information quality is defined as the degree to which system users think that online learning information is up-to-date, accurate, relevant, comprehensive, and organized" [38]. "Service quality is referred to through these attributes: tangible, reliability, responsiveness, assurance, functionality, interactivity, and empathy" [39].

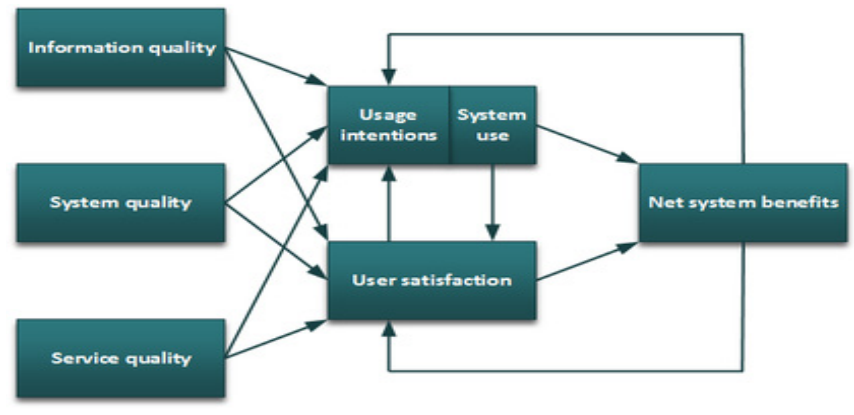

Figure 1: Information System Success Model (ISSM)
Previous studies used this model in the context of electronic learning. For example, the article [40] added transformational leadership in ISSM to study the adoption of online learning. They found that overall quality positively affects the adoption of online learning. Another study conducted by the article [36], results showed that quality dimensions which include; system quality, service quality, and information quality significantly affect user satisfaction of electronic learning.

In this regard, sseveral previous studies also used ISSM in different information systems contexts. The paper [41] investigated factors affecting the success of banking systems. The results showed that system quality, service quality, and information quality positively affect intention and acceptance of banking systems. The article [42] concluded that these 3 quality dimensions are core determinants in affecting users' trust and satisfaction of phone-call-related applications. The article [43] also found that these quality dimensions have a positive and direct impact in Accounting Information Systems (AIS) success at the organizational level. Table 1 summarizes the most important studies that have been conducted in adopting mobile learning. Through the table, it has been observed that most of these studies used two models, namely TAM and UTAUT2, while this study used ISS Model to increase and deepen the understanding regarding mobile learning as this model contains variables that have not been measured Sufficient in the previous studies.

Table 1: Previous studies in acceptance/adoption of mobile learning area

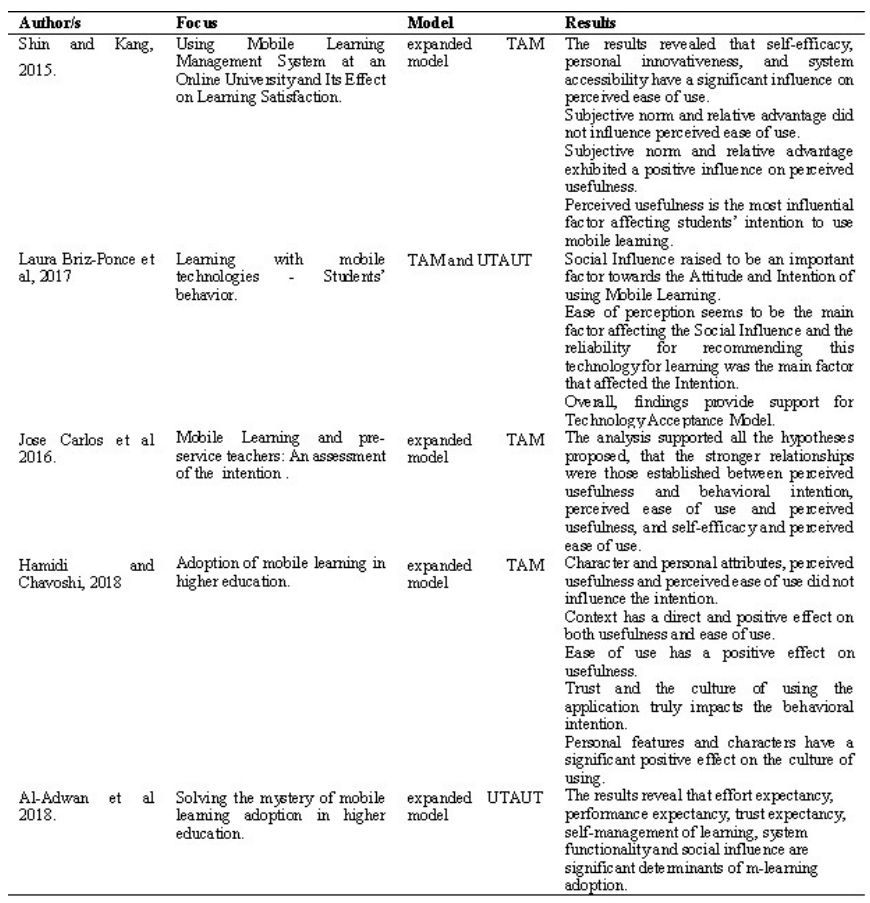

Based on positive recommendations and results of previous studies [44]. We extended ISSM by adding trust to develop an inclusive model for evaluating the intention to use mobile learning. These intentions will be increased when learners/students believe that mobile learning application is beneficial in their learning process. This study proposed four hypotheses as following:

H1: System quality positively affects intention to use mobile learning. 
H2: Service quality positively affects intention to use mobile learning.

H3: Information quality positively affects intention to use mobile learning.

\section{H4: Trust positively affects intention to use mobile learning.}

The present study depends on previous studies in developing the proposed research model and associated hypotheses. This study aims to discover the possible impact of trust and quality dimensions, which are information quality, service quality, and system quality on the intention to use mobile learning as see Figure 2 .

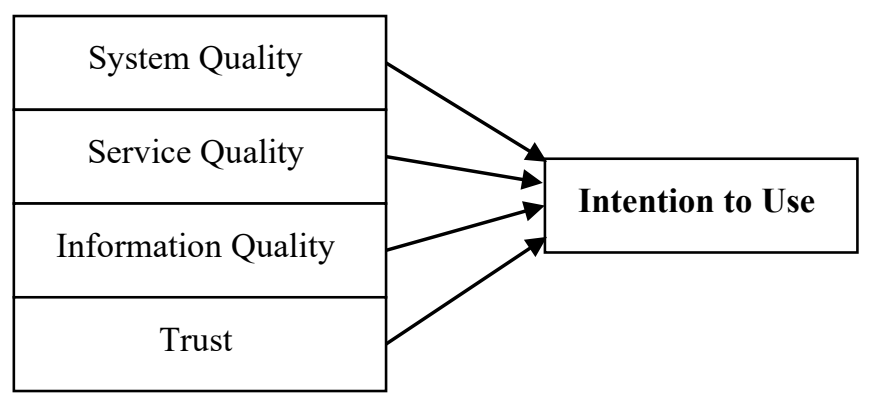

Figure 2: Proposed Research Framework

\section{Methodology}

The sample in this study was represented by university students enrolled in two Jordanian universities namely: The University of Jordan and Yarmouk University. A quantitative method (questionnaire) was used to collect the necessary data in this study, including two sections, the first section containing personal information of participants (gender, income, and internet frequency usage). In the second section covering 20 items to evaluate the four variables, a five Likert scale for all items was used with values from 1 "strongly disagree" to 5 "strongly agree". These items were carefully selected from related literature and different areas of IS/IT research. 480 answers were received. Out of these, 30 participants were not users of mobile learning, hence, these surveys were not included in this study. Besides that, 20 were incomplete and 12 answers were removed due to non-seriously in filling out (e.g. identical responses for each question). So 418 surveys were considered in this study for statistical analysis. The data collection period lasted twenty-five days between February 2 and February 27, 2020. Finally, SPSS version 23 was used to analyze data.

\section{Results and Discussion}

The results of the item-total correlation for each item exceeded the minimum acceptable value which is 0.5 as suggested by the article [45]. Cronbach's alphas also were measured for each construct. The result showed that all items were more than 0.70 therefore all items were kept for more statistical analysis. Besides, items of this study were loaded on the component matrix. It was be found that all coefficients were greater than the lowest acceptable level of 0.70 [46]. For hypotheses testing, all hypotheses in this study were accepted. Regarding H1, system quality (most significant factor) has been found positively affect intention to use mobile learning applications in Jordan $(\beta=0.293$, $\mathrm{p}<0.001)$. This result provides support for the articles [33, 34] findings based on ISSM. The results of prior studies also found system quality as a vital variable in using on-line learning, e.g., the study by the article [36] found that service quality is a vital variable in the adoption of online learning.

For H2, service quality has been found positively affect intention to use mobile learning $(\beta=0.261, p<0.001)$ which supports the result of the articles [33, 34] based on ISSM. The results of prior studies also found the service quality as a vital variable in using online learning, e.g., the study by the article [40] /found that the service quality is a vital variable in the adoption of online learning. For H3, information quality has been found positively affect intention to use mobile learning $(\beta=0.223, p<$ $0.001)$ which supports the result of the articles $[33,34]$ based on ISSM. The results of prior studies also found information quality as a vital variable in using on-line learning $[35,40]$. For H4, this study reveals the important role of trust in intention to use process $(\beta=0.115, p<0.01)$. This role has been found in other studies in the context of mobile learning by the paper [47] which they discovered that trust dimensions play a major role in influencing users to use mobile learning. The results of hypotheses testing are summarized in Figure 3.

The results offer valuable information for both top management and system designers regarding the enhancement of students' desire for the use of mobile learning. The current paper concluded that the presence of effective leadership and management support in universities leads to raising motivation of students to use mobile learning. According to survey results, the respondents have a good level of readiness to use such an application. This means that the level of conviction in the use of mobile learning among students depends greatly on the quality of the service provided to them, so the higher the quality of information, the quality of the system, and the quality of the service, this leads to a greater conviction for the use of this application. In addition, those responsible for these applications must provide updated, easy-to-understand, and complete information. In this way, the students' motivation will increase to use this service, since they will notice the many benefits as a result of using it. The justification for this positive path between the dimensions of quality and intention to use is that the Jordanian government has strengthened the communications infrastructure, and therefore the service provided is considered to be cheap and of high quality. This study found that the trust factor is very important in adopting mobile learning. This importance stems from that it motivates the student to use this application, as well as the student influences the decision of his/her colleagues to adopt such applications and thus the level of confidence affects the adoption of the service, in other words, the more confidence in the service increases, the greater the percentage Use it among students and vice versa.

During the last decade, and through an integrated plan by the government, Jordan has achieved tremendous development in terms of infrastructure in the field of communications. This strategic plan for the educational sector in moving towards mobile learning is in line with Queen Rania's vision, who believes that the general trend in the future in universities and schools will be in elearning. She always urges researchers to conduct more studies in order to motivate students to use this technology in education [18]. This trend in Jordanian universities towards e-learning would give these universities a competitive ability at the global level, which in 
turn raises the ranking of universities on approved standards such as THE and QS rankings. This important issue has increased the desire to realize the determinants that affect the students' intention to use mobile learning in higher education.

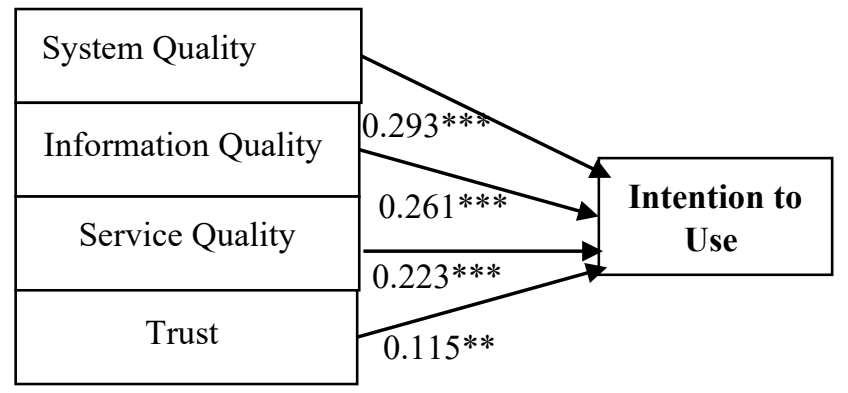

$* * \mathrm{p}<0.01, * * * \mathrm{p}<0.001$

Figure 3: Findings of path analysis

\section{Conclusion}

Technology is changing constantly, and the demand for smartphones is increasing. The many features of the smartphone have attracted many users around the globe. This leads to a higher demand for mobile learning and thus a change in the university education system. From a theoretical perspective, quality dimensions are a vital facet in electronic learning as well it has a high impact on the level of understanding. Besides that, the current study showed that trust in mobile learning applications has a positive effect, as well as high trust motivates the intention to use. However, this study can be improved by conducting a study include the public and private universities, in this way, a comprehensive model in the context of mobile learning can be constructed that extends quality dimensions and trust for local context applications.

\section{Limitations and Future Research}

This study contains several limitations, which are useful for future research. Firstly, the sample of this study was confined to academic institutions in Jordan, and therefore the difficulty of generalizing the results to other countries. Besides that, a sample of this study included only respondents using mobile learning, and those who do not use this service were excluded, so future studies can include users who are not satisfied with this service and study the reasons for refusing to use this service. Third, the moderate effect of demographic factors e.g. gender, income, and familiarity with mobile applications have not been taken into consideration, and it is expected that these factors will affect students' intention to use mobile learning. Finally, given that mobile learning is still in an early stage at the application level in educational and academic institutions in Jordan, therefore we recommend future studies to use the innovation diffusion theory [48] as it is very appropriate in the early stages before the diffusion of new technology.

\section{Conflict of Interest}

The authors declare no conflict of interest.

\section{References}

[1] Y.M. Huang, and P.S. Chiu, The effectiveness of a meaningful learningbased evaluation model for context-aware mobile learning. British Journal of Educational Technology, 46(2): 437-447, 2015. doi:10.1111/bjet.12147.
[2] G. Fulantelli, D. Taibi, and M. Arrigo, A framework to support educational decision making in mobile learning. Computers in human behavior, 47, 5059, 2015. doi.org/10.1016/j.chb.2014.05.045.

[3] M. Al-Okaily et al., Dataset on the Acceptance of e-learning System among Universities Students' under the COVID-19 Pandemic Conditions. Data in Brief, 2020. 32: 106176, doi.org/10.1016/j.dib.2020.106176.

[4] I. Han, and W.S. Shin, The use of a mobile learning management system and academic achievement of online students. Computers \& Education, 2016. 102:.79-89, doi.org/10.1016/j.compedu.2016.07.003.

[5] M. Al-Emran, H.M. Elsherif, and K. Shaalan, Investigating attitudes towards the use of mobile learning in higher education. Computers in Human behavior, 56: 93-102, 2016. doi.org/10.1016/j.chb.2015.11.033.

[6] H. Crompton, A historical overview of mobile learning: Toward learnercentered education. Handbook of mobile learning, 3-14, 2013.

[7] N.S. Alzaza, N.S. and A.R. Yaakub, Students' awareness and requirements of mobile learning services in the higher education environment. American Journal of Economics and Business Administration, 3(1): 95-100, 2011.

[8] S. Homan, and K. Wood, Taming the Mega-Lecture: Wireless Quizzing. Syllabus Magazine, October 7-8. 2003.

[9] M.A. Emran, and K. Shaalan. E-podium Technology: A medium of managing Knowledge at Al Buraimi University College via Mlearning. in Proceedings of the 2nd BCS International IT Conference 2014, doi.org/10.14236/ewic/bcsme2014.

[10] A. Abu-Al-Aish, and S. Love, Factors influencing students' acceptance of m-learning: An investigation in higher education. The International Review of Research in Open and Distributed Learning, 14(5): 82-107, 2013. doi.org/10.19173/irrodl.v14i5.1631.

[11] A. Matias, and D.F. Wolf, Engaging students in online courses through the use of mobile technology. Cutting-edge Technologies in Higher Education, 6 part (D): Emerald Group Publishing Limited, Bingley, 115-142, 2013. doi.org/10.1108/S2044-9968(2013)000006D007.

[12] A.I. Saroia, and S. Gao, Investigating university students' intention to use mobile learning management systems in Sweden. Innovations in Education and Teaching International, 56(5): 569-580, 2019. doi.org/10.1080/14703297.2018.1557068.

[13] B. Handal, J. MacNish, and P. Petocz, Adopting mobile learning in tertiary environments: Instructional, curricular and organizational matters. Education Sciences, 3(4): 359-374, 2013. doi:10.3390/educsci3040359

[14] F. Mubuke, et al., The Predictability of Perceived enjoyment and Its Impact on the intention to use Mobile learning systems. Asian Journal of Computer Science And Information Technology, 1(1): 1-5, 2017. doi.org/10.15520/ajcsit.v6i851.

[15] M.A. Almaiah, M.M. Alamri, and W.M. Al-Rahmi, Analysis the effect of different factors on the development of Mobile learning applications at different stages of usage. IEEE Access, 8: 16139-16154, 2019. 10.1109/ACCESS.2019.2963333.

[16] B. Pynoo, et al., Predicting secondary school teachers' acceptance and use of a digital learning environment: A cross-sectional study. Computers in Human behavior, 27(1): 568-575, 2011. DOI: 10.1016/j.chb.2010.10.0

[17] S. Criollo, S. Luján, and A. Jaramillo. Advantages and disadvantages of Mlearning in current education. in World Engineering Education Conference (EDUNINE). IEEE, 2018. DOI: 10.1109/EDUNINE.2018.8450979.

[18] M.A. Almaiah, M.A. Jalil, and M. Man, Extending the TAM to examine the effects of quality features on mobile learning acceptance. Journal of Computers in Education, 3(4): 453-485, 2016. doi.org/10.1007/s40692-0160074-1.

[19] A. Chavoshi, A. and H. Hamidi, Social, individual, technological and pedagogical factors influencing mobile learning acceptance in higher education: A case from Iran. Telematics and Informatics, 38: 133-165, 2019. doi.org/10.1016/j.tele.2018.09.007.

[20] 20. Almaiah, M.A. and O.A. Alismaiel, Examination of factors influencing the use of mobile learning system: An empirical study. Education and Information Technologies, 2019. 24(1): 885-909, doi.org/10.1007/s10639018-9810-7

[21] L. Briz-Ponce, and J.A. Juanes-Méndez, Mobile devices and apps, characteristics and current potential on learning. Journal of Information Technology Research (JITR), 8(4): 26-37, 2015. 10.4018/JITR.2015100102.

[22] M.K. Gharaibeh, and M.R.M. Arshad, Determinants of intention to use mobile banking in the North of Jordan: extending UTAUT2 with mass media and trust. Journal of Engineering and Applied Sciences, 13(8): 2023-2033, 2018. dx.doi.org/10.36478/jeasci.2018.2023.2033.

[23] The Jordan Times, ICT, Internet usage among Jordanian households increases - ministry. 2018.

[24] M.K. Gharaibeh, and M.R.M. Arshad, The Impact of Demographic Factors and Visual Aesthetics of Mobile Application Interface on Intention to Use 
Mobile Banking in Jordan. Journal of Theoretical \& Applied Information Technology, 96(4): 937-945, 2018.

[25] Gharaibeh, M.K., N.K. Gharaibeh, and M.V. De Villiers, A Qualitative Method to Explain Acceptance of Mobile Health Application: Using Innovation Diffusion Theory. International Journal of Advanced Science and Technology, 2020. 29(4): 3426-3432.

[26] GCI, Jordan GCI 2018. 2018.

[27] M. Gharaibeh, and M.R.M. Arshad, Current status of mobile banking services in Jordan. World Applied Sciences Journal, 34(7): 931-935, 2016. 10.5829/idosi.wasj.2016.34.7.153.

[28] M. Gharaibeh, M.R. Arshad, and N.K. Gharaibeh, Using the UTAUT2 model to determine factors affecting adoption of mobile banking services: A qualitative approach. International Journal of Interactive Mobile Technologies (iJIM), 12(4): 123-134, 2018.doi.org/10.3991/ijim.v12i4.8525.

[29] N. Gharaibeh, et al., Exploring Intention to use Mobile Commerrce: Integrating UTAUT2 with Social Media. International Journal of Scientific and Technology Research, 9(3): 3826-3833, 2020.

[30] L. Briz-Ponce, et al., Learning with mobile technologies-Students' behavior. Computers in Human Behavior, 72: 612-620, 2017. doi.org/10.1016/j.chb.2016.05.027.

[31] P. Sánchez, M.S. Olmos, and P.F.J. García, MLearning and pre-service teachers: An assessment of the behavioral intention using an expanded TAM model. Computers in Human Behavior, 72: 644-654, 2017. doi.org/10.1016/j.chb.2016.09.061.

[32] H. Hamidi, and A. Chavoshi, Analysis of the essential factors for the adoption of mobile learning in higher education: A case study of students of the University of Technology. Telematics and Informatics, 35(4): 1053-1070, 2018. doi.org/10.1016/j.tele.2017.09.016.

[33] W.H. Delone, and E.R. McLean, The DeLone and McLean model of information systems success: a ten-year update. Journal of management $\begin{array}{llll}\text { information } & \text { 19(4): } & \text { 9-30, } & 2003 .\end{array}$ doi.org/10.1080/07421222.2003.11045748.

[34] W.H. DeLone, and E.R. McLean, Information systems success: The quest for the dependent variable. Information systems research, 3(1): 60-95, 1992. doi.org/10.1287/isre.3.1.60.

[35] A.H. Aldholay, et al., The role of compatibility as a moderating variable in the information system success model: The context of online learning usage. International Journal Of Management And Human Science, 2(1): 9-15, 2018.

[36] R. Freeze, et al., IS success model in e-learning context based on students' perceptions. Journal of Information systems education, 21(2): 173-184, 2019.

[37] S. Petter, and E.R. McLean, A meta-analytic assessment of the DeLone and McLean IS success model: An examination of IS success at the individual level. Information \& Management, 46(3): 159-166, 2009. doi.org/10.1016/j.im.2008.12.006.

[38] T. Acton, et al., DeLone \& McLean success model as a descriptive tool in evaluating the use of a virtual learning environment, in International Conference on Organizational Learning, Knowledge and Capabilities. 2009.

[39] F. Lin, S.S. Fofanah, and D. Liang, Assessing citizen adoption of eGovernment initiatives in Gambia: A validation of the technology acceptance model in information systems success. Government Information Quarterly, 28(2): 271-279, 2011. doi.org/10.1016/j.giq.2010.09.004.

[40] A.H. Aldholay, et al., The role of transformational leadership as a mediating variable in DeLone and McLean information system success model: The context of online learning usage in Yemen. Telematics and Informatics, 35(5): 1421-1437, 2018. doi.org/10.1016/j.tele.2018.03.012.

[41] A. Jaafreh, Evaluation information system success: Applied delone and McLean information system success model in context banking system in KSA. International Review of Management and Business Research, 6(2): 829-845, 2017.

[42] C. Lin, and Y.-J. Chang. The Application of IS Success Model on Continuous Intention and Information Sharing for Caller ID Apps Usage. in International Conference on HCI in Business, Government, and Organizations, Springer, 2018.

[43] A. Al-Okaily, et al., Measuring Success of Accounting Information System: Applying the DeLone and McLean Model at the Organizational Level. Journal of Theoretical and Applied Information Technology, 98(14): 2697$2706,2020$.

[44] A. Al-Okaily, et al., Accounting information system effectiveness from an organizational perspective. Management Science Letters, 10(16): 3991-4000, 2020. $10.5267 /$ j.msl.2020.7.010.

[45] J. Hair, et al., Multivariate data analysis: A global perspective. 7, Pearson Upper Saddle River, NJ, 2010:

[46] A. Field, Discovering Statistics Using SPSS (2nd ed). London: Sage Publications, 2005.
[47] E. Ibrahim, and N. Walid, Trust contributing factors in m-learning technology. Procedia-Social and Behavioral Sciences, 129: 554-561, 2014. 10.1016/j.sbspro.2014.03.713.

[48] E.M. Rogers, Diffusion of innovations.Simon and Schuster, 2010. 